\title{
TINGKATAN DAN METODE TOBAT
}

\author{
Abdur Rohman \\ Dosen Ilmu Tasawuf IAI Pangeran Diponegoro Nganjuk \\ abdurrohman@iaipd-nganjuk.ac.id
}

\begin{abstract}
Abstrak
Dalam kajian tasawuf ada istilah maqamāt (tingkatan-tingkatan) untuk menuju Allah. Sedangkan tingkatan terbawah dari maqamat adalah tobat. Oleh sebab itu, level awal yang harus dilalui oleh seorang sătik adalah tobat. Jika pada level ini belum selesai, maka seorang sălik tidak layak untuk 'naik kelas'. Artikel ini membahas tingkatan tobat beserta metode untuk bertobat. Tingkatan tobat ada empat, yaitu tobat dari dosa besar dan kecil, tobat dari perkara makruh serta tobat dari perkara mushbät. Sedangkan metode agar cepat tobat adalah: Pertama, memikirkan orang-orang yang mati mendadak. Kedua, merenungkan kisah Fir'aun yang ingin tobat dipenghujung hayat saja. Ketiga, penentuan husn al-khätimah adalah kebiasaan.
\end{abstract}

Kata kunci: tobat, al-qur'an, hadis.

\section{Pendahuluan}

Tobat dalam bahasa Indonesia diterjemahkan dengan sadar dan meyesal akan dosa atau kesalahan yang telah dilakukan dan berniat akan memperbaiki tingkah lakunya. ${ }^{1}$ Sedangkan dalam bahasa Arab, tobat dimaknai dengan al-nadm (menyesal). Menyesal yang dimaksud adalah menyesali dosa-dosanya dan kembali taat kepada Allah. ${ }^{2}$ Jika seseorang menyatakan bertobat tetapi ia masih mengulangi lagi kesalahannya, maka hal itu belum termasuk kategori tobat.

1 Pusat Bahasa Departemen Pendidikan Nasional, Kamus Bahasa Indonesia. Jakarta: Pusat Bahasa Departemen Pendidikan Nasional, 2008, 1534.

2 Ibn Manzur, Lisān 'Arab. Kairo: Dār al-Ma'ārif, 1119, 454.

Spiritualis, vol. 5, no. 1, Maret 2019

ISSN: 2442-5907|19 
Dalam kajian tasauwf, tobat merupakan level terbawah ${ }^{3}$ dalam maqāmàt (tingkatan menuju Allah). ${ }^{4}$ Oleh karena itu, seseorang sălik (orang yang menempuh jalur sufi menuju Allah) 'tidak layak' untuk menginjak tingkatan di atasnya jika dalam tingkatan dasar ini tidak lulus. Artikel ini akan mengulas tentang tingkatan tobat beserta cara agar seseorang cepat bertobat.

\section{Tingkatan Tobat ${ }^{5}$}

Seseorang dikatakan berhasil bertobat pada saat ia bisa berhenti dari kesalahan-kesalahan atau dosa yang ia perbuat. Namun apabila merasa berat secara langsung untuk menghentikan seluruh dosa-dosa yang terbiasa dilakukan, alangkah baiknya berlatih dari tahapan yang paling besar. Sebab, jika yang besar bisa dihentikan, biasanya yang kecil akan lebih mudah.

Tahap pertama, tobat dari dosa besar. Kategorisasi dosa besar telah digariskan oleh Rasulullah yaitu, syirik, membunuh orang, durhaka kepada kedua orang tua dan bersaksi palsu. ${ }^{6}$ Di bawah dosa tersebut adalah mencuri, berzina, minum-minuman keras dan sebagainya. 'Umar bin Khațāa dulu sebelum masuk Islam merupakan raja mabuk dan preman di pasar Ukaz. ${ }^{7}$ Namun setelah masuk Islam dan ayat al-Qur'an turun yang mengharamkan khamr, 'Umar menghentikan kebiasaan itu, begitu juga oleh kaum muslimin yang lain.

${ }^{3}$ Mahjuddin, Akblak Tasawnf I: Mukizat Nabi, Karomah Wali dan Ma'rifah Sufi. Jakarta: Kalam Mulia, 2011, 225; Ris'an Rusli, Tasawuf dan Tarekat: Studi Pemikiran dan Pengalaman Sufi. Jakarta: Raja Grafindo Persada, 2013, 55.

4 Mustari Mustafa, Agama dan Bayang-bayang Etis, Syaikh Yusuf al-Makassari. Yogyakarta: LKiS, 2011, 77.

${ }^{5}$ Ris'an Rusli, 45.

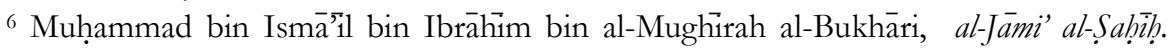
Kairo: Dār al-Shu'ab, 1987, vol. 3, 224; nomor hadis 2653.

7 Muhammad Husain Haekal, Umar bin Khattăb, terj, Ali Audah. Jakarta: Litera AntarNusa, 2013, 1-2.

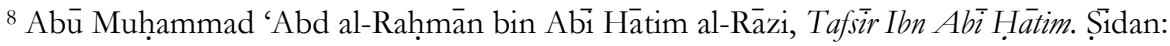
al-Maktabah al-'Așriyah, t. th, vol. 2, 388. 
Jika seseorang telah selesai dari dosa-dosa besar dan dosa sedang, maka sudah saatnya untuk menghentikan dosa-dosa kecil. Tobat dari dosa-dosa kecil seperti berbuat jail kepada teman, mencuri permen, tidak menepati janji dan sebagainya.

Tobat selanjutnya adalah tidak melakukan perbuatan makruh. Makruh adalah perkara yang tidak haram dilakukan namun termasuk perkara yang tidak disenangi oleh orang lain dan orang yang meninggalkan perkara makruh akan mendapatkan pahala. Contoh perbuatan makruh adalah makan-minum sambil berjalan atau berdiri, merokok, makan makanan yang memiliki bau menyengat dan tidak segera membersihkan mulutnya, berenang saat berpuasa, serta perkaraperkara yang tidak ada larangan dalam al-Qur'an maupun hadis secara tegas, akan tetapi membuat orang lain tidak nyaman. Itu adalah makruh.

Level di bawahnya adalah tobat dari perkara shubhät. Shubbat memiliki arti 'samar-samar'. Artinya, perkara yang belum jelas status hukumnya, baik status halal atau haram. Contoh perkara shubhat seperti makan makanan dari kemungkinan hasil korupsi, menerima upah dari terduga uang hasil pekerja seks dan sebagainya. Jika sebagian dari perkara-perkara di atas tersebut masih ada yang dilakukan oleh seorang sälik, maka dia belum bisa naik level karena di level terbawah dalam maqāāt belum lulus.

\section{Metode Tobat}

Kata tawbah di dalam al-Qur'an disebutkan sebanyak 6 kali. ${ }^{9}$ Salah satunya terdapat di dalam surah al-Taḥīim [66] ayat 8:

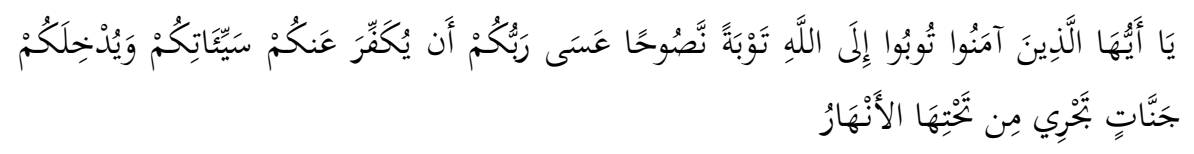

${ }_{9}$ Muḥammad Fu'ad 'Abd al-Bāqi, al-Mu'jam al-Mufahras li Alfă al-Qur'an al-Karim. Kairo: Dār al-Kutub al-Mișrìyah, 1364, 157. 
Wahai orang-orang yang beriman, bertobatlah kepada Allah dengan tobat yang semurni-murninya, mudah-mudahan Tuhan kamu akan menghapus kesalahan-kesalahanmu dan memasukkanmu ke dalam surga-surga yang mengalir di bawahnya sungai-sungai.

Ayat ini memberikan perintah agar umat manusia bertobat atas kesalahannya. Kemudian jika dia benar-benar bertobat, maka Allah swt. akan memberikan balasan berupa surga dengan segala kenikmatannya. Perintah tersebut tidak disertai dengan metode bagaimana caranya agar seseorang bisa bertobat atas kesalahan-kesalahannya. Oleh karena itu, dibutuhkan metode khusus yang membahas tentang tobat agar perintah al-Qur'an ini bisa terlaksana dengan baik. Berikut adalah beberapa metode agar seseorang bisa cepat bertobat.

Pertama, mengingat banyaknya orang yang meninggal mendadak. Di lingkungan kita tidak sedikit cerita bahwa ada orang yang meninggal dunia secara mendadak. Misalnya ada cerita tentang seseorang yang meninggal dunia pada saat makan. Makanan belum sampai ditelan ke dalam perut, sudah di panggil Tuhan. Tidak sedikit orang yang meninggal dunia padahal ia masih enak-enakan menikmati secangkir kopi. Kopi belum sampai habis ajal juga telah menjemputnya. Belum lagi orang yang kecelakaan di jalan.

Sebelumnya mungkin orang tersebut bersenda gurau dengan kawan, famili atau orang-orang dekat yang ada di sekitarnya. Namun siapa sangka bahwa Tuhan memanggilnya terlebih dahulu. Peristiwa seperti ini akan membuat orang sekitarnya tidak percaya, sebab kepergiannya begitu mendadak. Kepergian orang-orang dekat yang mendadak tersebut tidak perlu disesali. Apakah dengan menyesali orang tersebut akan dihidupkan kembali? Tentu tidak!

Peristiwa kepergian orang yang meninggal secara mendadak tersebut seharusnya menjadi peringatan bagi orang yang masih hidup bahwasannya kita harus selalu waspada. Sebab, sewaktu-waktu ajal itu tiba, kita bisa siap dan segera mengakhiri kemaksiatan kepada Tuhan. Masih beruntung bagi orang-orang yang meninggal dunia pada saat ia 
beramal saleh. Akan tetapi bagaimana dengan orang yang penghujung hayatnya tidak beramal saleh? Tentu dengan bertobat kita akan semakin siap kalau sewaktu-waktu Tuhan menjemput kita.

Mungkin ada - atau bahkan banyak - orang yang memiliki pemikiran bahwa bertobatnya nanti saja pada saat sudah tua dan rajin untuk beribadah. Ungkapan ini mungkin hanya sebatas angan-angan dan belum tentu menjadi kenyataan. Sebab, jika ajal menjemput, belum lagi ia bertobat sudah terlebih dahulu dipanggil oleh Tuhan. Ada kisah seorang raja yang mau bepergian. Saat itu ia ingin mengenakan pakaian terbaik dan kuda terbaik. Baju dan kendaraan (kuda)nya dipersiapkan oleh seorang pembantu. Namun tidak ada yang pas, lalu ia memilih sendiri baju kebesaran dan kendaraan pilihannya. Di tengah jalan, ia berjalan dengan congkak lalu bertemu dengan pria tua compangcamping.

Pria tua yang compang-camping itu kemudian meminta agar sang raja turun dari kudanya. Sang raja marah dan memerintahkan agar si tua itu menyingkir dari jalannya. Namun ternyata pria tua itu tidak mau berpindah dari jalan tersebut sebelum sang raja mau berbicara langsung kepadanya. Akhirnya sang raja mau berbicara dengan pria tua tersebut. Sang raja bertanya 'siapakah engkau'? Pria tua itu menjawab 'Saya adalah Izra'il'? Mendengar jawaban itu sang raja langsung gemetar dan meninggal dunia saat itu juga.

Bertobat dengan menunda-nunda waktu hingga tua mungkin saja ada dalam pemikiran seseorang. Beribadah atau bertobat masih menunggu masa tua? Iya kalau umurnya sampai tua, kalau tidak? Penulis tidak sedikit mendengarkan perkataan orang yang sudah tua 'kalau sudah tua begini mau kemana-mana sudah tidak. kuat, mau baca al-Qur'an pandangan mata sudah tidak jelas, mau memperbanyak, shalat sunah fisik tidak, kuat? Jika seperti itu, bukankah menunggu masa tua untuk ibadah atau untuk bertobat hanyalah isapan jempol? Bukankah ada riwayat yang menyatakan bahwa: 


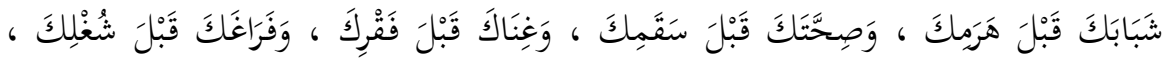

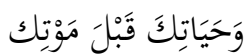

Mudamu sebelum pikunmu, sehatmu sebelum sakitmu, kayamu sebelum fakirmu, luangmu sebelum sibukmu dan hidupmu sebelum matimu. ${ }^{10}$

Ungkapan ini menegaskan bahwa agar manusia memaksimalkan keadaannya pada saat itu juga. Bisa jadi pada saat kondisi sedang tidak memungkinkan ia akan menyesali perbuatnnya. Mengapa tidak saat ini juga diakhiri?

Banyaknya cerita tentang orang-orang yang diambil Tuhan secara mendadak membuktikan bahwa Tuhan adalah Maha Kuasa. Bukankah ada hadis yang menyebutkan bahwa:

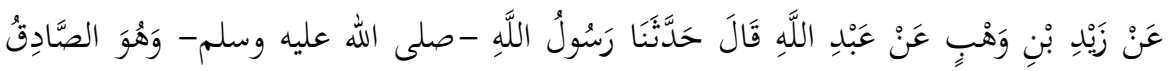

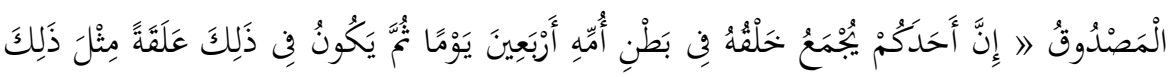

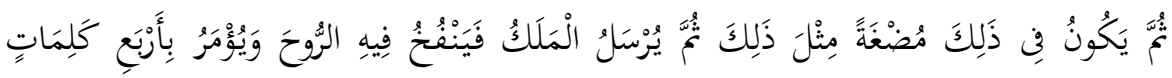

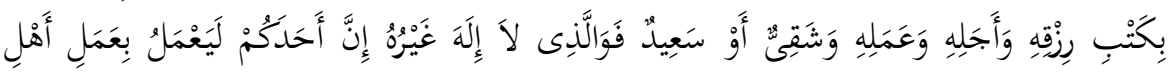

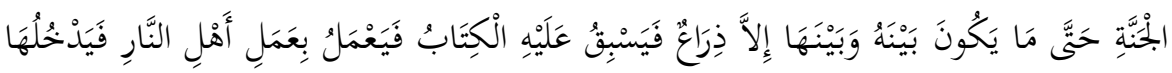

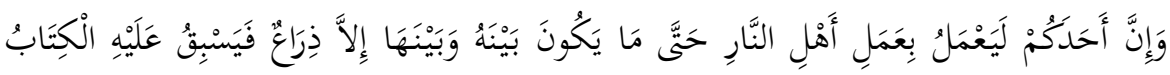

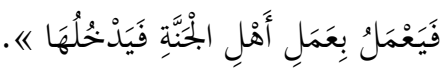

Dari Zaid bin Wahab dari 'Abd Allāh berkata, Nabi saw. bersabda: sesungguhnya salah satu diantara kalian dikumpulkan dalam rahim ibu selama empat puluh hari lalu setelah masa itu menjadi 'alaqah (bentuk sejenis lintah yang menempel pada dinding rahim) lalu setelah masa itu (empat puluh hari) menjadi mudhghah (segumpal daging) lalu diperintahkan Malaikat untuk meniupkan ruh ke dalamnya dan

10 Abū 'Abd Raḥmān Aḥmad bin Shu'aib bin 'Ali al-Nasā'ì, al-Sunan al-Kubrā. alMaktabah al-Shāmilah al-Iṣdār Thāni, nomor hadis, 11832. 
(Malaikat tersebut) diperintahkan untuk mencatat empat kalimat. Rezeki, ajal (ketetapan batas umur), dan amalnya, baik yang beruntung atau celaka. Demi Dzat yang yang tiada tuhan selain-Nya. Sesungguhnya kamu sekalian apabila melakukan amal ahli surga sehingga jarak antara dirinya dan surga hanya satu dhira', (sekitar ukuran $60 \mathrm{~cm}$ ). Namun jika sudah di tetapkan sebelumnya, maka ia melakukan amal ahli neraka, maka masuklah ia ke sana. Sesungguhnya kamu sekalian beramal dengan amalnya ahli neraka, sehingga jarak antara dirinya dengan neraka itu hanya satu dbirá, namun telah didahului ketetapan, maka ia melakukan amal seperti amalnya ahli surga, maka masuklah ia ke sana. (HR. Muslim, 6893).

Dalam al-Qur'an Allah menyatakan bahwa ida jäa ajlubum là yasta'kbirūna sä'atan wala yastaqdimün (ketika ajal mereka telah tiba, maka tidak bisa diakhirkan atau diajukan). Ayat dan hadis ini memberikan gambaran yang sangat jelas bahwa batasan ajal manusia telah di gariskan oleh Tuhan dan ketika sampai pada batasan itu tiada satupun orang yang dapat mengelak dari panggilan Tuhan. Untuk itu, karena tiada satupun orang yang mengetahui ajalnya. Manusia harus selalu waspada dan segera mengakhiri kemaksiatannya. Sebab jika sewaktu-waktu ajal itu tiba, manusia tidak bisa berbuat apa-apa.

Kedua, tadabbur tentang kisah Fir'aun. Jika manusia hanya ingin bertobat di penghujung hayat, maka ia sama dengan Fir'aun. Bukankah Fir'aun mengetahui bahwa sebenarnya penentuan sebuah perjalanan hidup seseorang adalah di penghujung hayat (ḅusn al-khatimab)? Dengan politik ini akhirnya Tuhan tidak merelakan ia untuk bertobat.

Allah berfirman dalam surat Yünus [10] ayat 90-91:

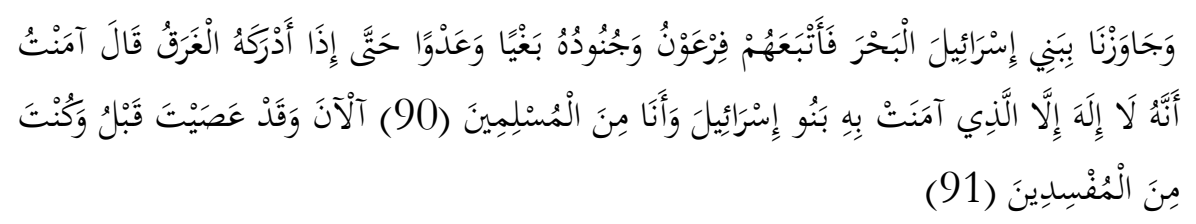


Dan Kami selamatkan Bani Isrāîl melintasi laut, kemudian Fir'aun dan bala tentaranya mengikuti mereka, untuk menzalimi dan menindas mereka. Sehingga ketika Fir'aun hampir tenggelam dia berkata "Aku percaya bahwa tidak ada tuhan melainkan Tuhan yang dipercayai oleh Bani Isrāîl dan aku termasuk orang-orang Muslim." Mengapa baru sekarang (kamu beriman), padahal sesungguhnya engkau telah durhaka sejak dahulu, dan engkau termasuk orang yang berbuat kerusakan.

Ayat ini merupakan kisah yang relevan dalam menjelaskan tobat. Raja Fir'aun sebenarnya ingin iman kepada Tuhan-nya Bani Isrāil yang telah didakwahkan oleh nabi Müsa. Akan tetapi dia mengulur waktu sampai nanti ketika ajal mau menjemput. Tetapi keengganan Fir'aun untuk tobat tersebut digagalkan oleh Allah dan Allah menegurnya 'mengapa baru sekarang (kamu beriman), padahal sesunggubnya engkau telah durbaka sejak dulu'. Dengan demikian, Allah memberikan signal bahwa tobat itu tidak diperkenankan hanya melirik pada saat ajal akan menjemput. Tetapi harus melalui cara yang benar sehingga memperoleh husn al-khatimah.

Ketiga, penentuan busn al-khatimah adalah kebiasaan. Prosentase baik dan buruknya akhir perjalanan hidup seseorang adalah berasal dari kebiasaan. Kisah Fir'aun di atas memberikan signal bahwa mempermainkan tobat bisa berakibat fatal, karena Allah tidak ridha terhadap perbuatan tersebut. Jika seseorang membiasakan diri melakukan perkara baik, maka potensi untuk ḅusn al-khätimah juga semakin besar. Begitu pula sebaliknya.

Orang yang mengamalkan tarekat tertentu misalnya, ia terbiasa dengan dzikir yang sangat banyak, baik dalam keadaan jabr atau sirri. Baik dalam keadaan sibuk atau lapang. Baik setelah shalat fardlu atau dalam beraktifitas. Semua kegiatan itu ia isi dengan berdzikir kepada Allah. Jika hal ini sudah menjadi kebiasaan, maka tidak heran jika lisannya selalu ingat Allah dalam keadaan apapun. Oleh karena itum tidak 
heran jika sewaktu-waktu diambil oleh Allah, keadaan dia dalam kondisi beramal saleh dan mendapatkan ḥusn al-khatimah.

Kebiasaan itu juga mempengaruhi prilaku atau ucapan seseorang. Orang yang terbiasa berdzkir, pada saat ia terjatuh atau terkena musibah, ia akan menyebut Allah karena itu sudah menjadi gerak reflek bagi mulutnya yang terbiasa berdzikir. Begitu juga sebaliknya. Orang yang terbiasa mengucapkan kata-kata kotor akan menyebut sesuatu yang kotor itu saat terjatuh atau terkena musibah. Bisa jadi, dalam kebiasaan seperti itulah ia akan diambil oleh Allah.

Otak bawah sadar manusia juga akan mengingat kebiasaan saat ia tersadar. Sangat jauh kemungkinannya orang yang tidak pernah berdzikir bisa berdzikir pada saat sakarat al-mawt. Hal ini dikarenakan saat sakarat al-mawt manusia sangat kesulitan untuk mengucapkan sesuatu. Apalagi jika sesuatu yang ingin diucapkan itu tidak terbiasa. Oleh karena itu, dalam kondisi setengah sadar, yang bisa mengingatkan dia kepada sesuatu adalah memorinya.

Jika di dalam memorinya selalu ada nama Allah, maka secara tidak sadar ia akan terbawa oleh nama itu sampai akhir hayat. Namun jika di alam bawah sadarnya adalah kebiasaan dengan menyebut katakata kotor, bisa sangat mungkin yang keluar dari mulutnya adalah perkataan itu yang sudah tertanam kuat di dalam otak bawah sadar. Oleh karena itu, tobat dan ḥusn al-khatimah tidak bisa dilakukan dengan instan dengan menunggu waktu tua. Akan tetapi bisa diupayakan dengan memperbanyak dzikir dan bertobat agar memperoleh ḅusn alkhatimah.

\section{Kesimpulan}

Kesimpulan dari artikel ini adalah tingkatan tobat itu dibagi menjadi empat bagian yaitu tobat dari dosa besar dan sedang, tobat dari dosa-dosa kecil, tobat dari perkara yang makrūh, dan tobat dari perkara yang syubhat. Sedangkan metode untuk bertobat adalah mengingat orang-orang yang mati mendadak. Kedua, merenungi kisah 'politik' 
Fir'aun yang ingin bertobat di penghujung hayat saja. Ketiga, segera bertobat adalah kunci untuk mendapatkan husn al-khatimah. Mengingat busn al-khatimah bisa didapat dari kebiasaan berdzikir. Oleh karena itu, jika ia tidak segera tobat dan membiasakan diri mengucapkan kalimat tayyibat/dzikir, maka bisa jadi ia akan kesulitan mengucapkan kalimat tayyibat tersebut. Hal ini disebabkan oleh kondisi sakarat al-mawt adalah kondisi di alam bawah sadar. Sedangkan yang akan diucapkan oleh orang yang berada di posisi bawah sadar adalah kebiasaannya saat masih sadar. Jika tidak pernah berdzikir atau beribadah, bagaimana mungkin husn al-khatimah didapatkan. 
Spiritualis, vol. 5, no. 1, Maret 2019|29

\section{DAFTAR PUSTAKA}

Bukhāri (al),Muhammad bin Ismā̄̄il bin Ibrāhīm bin al-Mughïrah. alJāmi’ al-Ṣaḩị̣. Kairo: Dār al-Shu’ab, 1987.

Haekal, Muhammad Husain. Umar bin Khațāb, terj, Ali Audah. Jakarta: Litera AntarNusa, 2013.

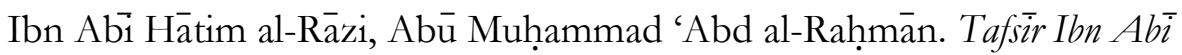
Hätim. Șidan: al-Maktabah al-'Așriyah, t. th.

Mahjuddin, Akblak Tasawnf I: Mukizat Nabi, Karomah Wali dan Ma'rifah Sufi. Jakarta: Kalam Mulia, 2011.

Manzur, Ibn. Lisān 'Arab. Kairo: Dār al-Ma’’arif, 1119.

Muhammad Fu'ad 'Abd al-Bāāi, al-Mu'jam al-Mufahras li Alfẵal-Qur'an al-Karìm. Kairo: Dār al-Kutub al-Mișrīyah, 1364.

Mustafa, Mustari. Agama dan Bayang-bayang Etis, Syaikh Yusuf alMakassari. Yogyakarta: LKiS, 2011.

Nasā̄i (al), Abū 'Abd Raḥmān Aḥmad bin Shu'aib bin 'Ali. al-Sunan alKubrā. al-Maktabah al-Shämilah al-Iṣdār Thāni.

Rusli, Ris'an. Tasawuf dan Tarekat: Studi Pemikiran dan Pengalaman Sufi. Jakarta: Raja Grafindo Persada, 2013.

Tim, Pusat Bahasa Departemen Pendidikan Nasional, Kamus Bahasa Indonesia. Jakarta: Pusat Bahasa Departemen Pendidikan Nasional, 2008. 